\title{
World Bank defends efforts to curb malaria
}

The World Bank has been forced to rebut a series of stinging criticisms from public-health commentators. They have accused it of failing to fulfil its promise to provide funds and leadership for Africa's fight against malaria.

Last year, the World Bank made a fresh pledge to implement global antimalaria schemes worth up to US\$1 billion over the next five years. This week's accusations mark the latest chapter in an acrimonious battle between the bank and a group of advocates who think it should hand the pledged funds over to agencies that, they argue, have greater public-health expertise.

The bank pledged in 2000 to make between $\$$ US300 million and $\$ 500$ million available to African governments for antimalaria treatments and infrastructure. But the bank's critics point out that by 2005 , no more than $\$ 150$ million had been provided.

"In 2000, they made the largest ever promise to spend money on malaria in Africa," says Amir Attaran, a law professor at the University of Ottawa, Canada, and lead author of a commentary that sets out the criticisms in this week's issue of The Lancet (A. Attaran et al. Lancet doi:10.1016/S0140-6736(06)68545-0; 2006). 'It's now 2006, and they have broken that promise." The commentary is co-authored by 12 epidemiology and public-health experts, from Africa, Europe and North America.

Bank officials admit that their initial drive was unsuccessful, partly because they did not receive as many applications from African governments as they expected. But they point out that the 2005 pledge, which aims to help the global Roll Back Malaria initiative hit its 2010 target of halving malaria cases, is already making progress.

"These criticisms are a year out of date, Suprotik Basu, a member of the bank's malaria team, told Nature. He says that, since the effort was relaunched last year, projects worth a total of $\$ 190$ million have been approved in Eritrea, Niger, Zambia and the Democratic Republic of Congo, and that the total will stand at $\$ 400$ million by July next year.

The bank will provide roughly half of the money itself. It will broker deals with other banks and with nongovernment organizations such as the Seattlebased Bill and Melinda Gates Foundation to raise the remainder of the cash. But Attaran complains that the bank, which has an annual tax-funded budget of $\$ 20$ billion, initially promised to raise all the funds by itself.

\section{Charges levelled}

More seriously, Attaran and his colleagues accuse the bank of massaging figures from previous malaria projects in Brazil and India to make them seem more successful. They also charge it with endorsing treatment options in India that will leave millions exposed to resistant forms of the disease.

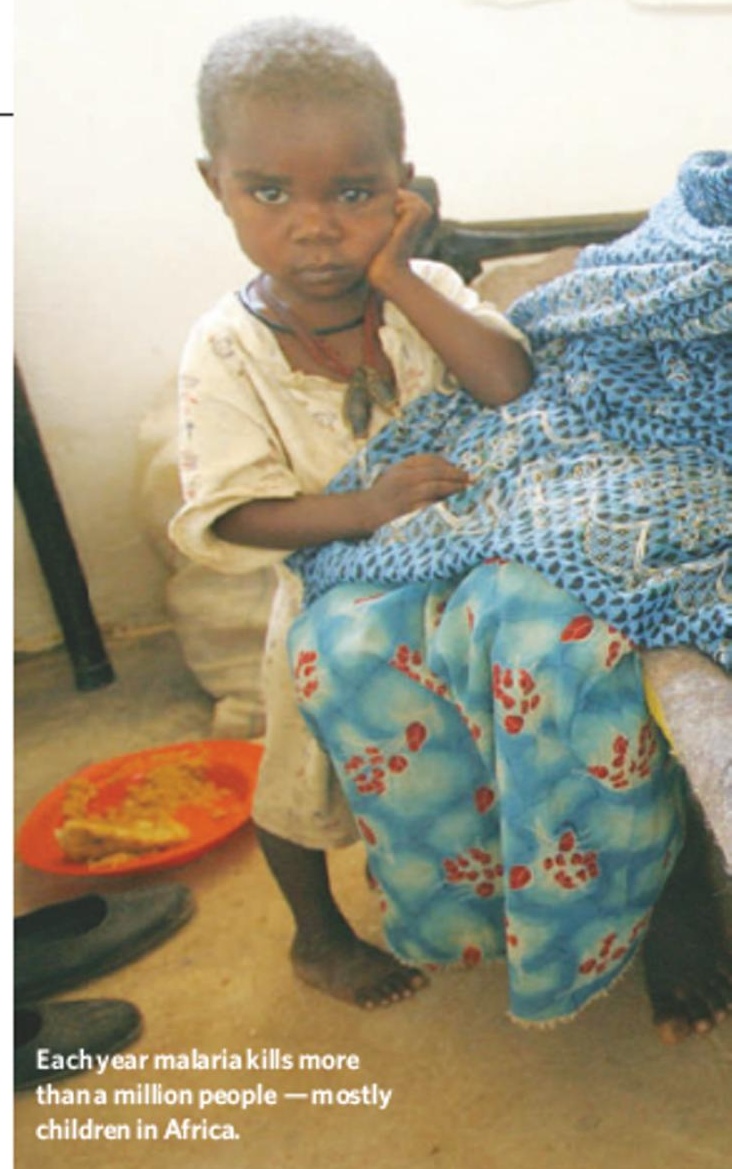

Basu describes the allegations as "flat wrong". Data used to compile the bank's figures, given to Attaran upon request, came from peerreviewed studies, and were neither collected nor doctored by the bank. And Basu insists that the bank is working closely with the World Health Organization (WHO) to ensure that the treatments it funds are recommended ones.

Whereas most malaria in Africa is spread by the Plasmodium falciparum parasite and ideally treated using drugs called artemisinins, around half of Indias cases are caused by P. vivax, and can be treated using the much

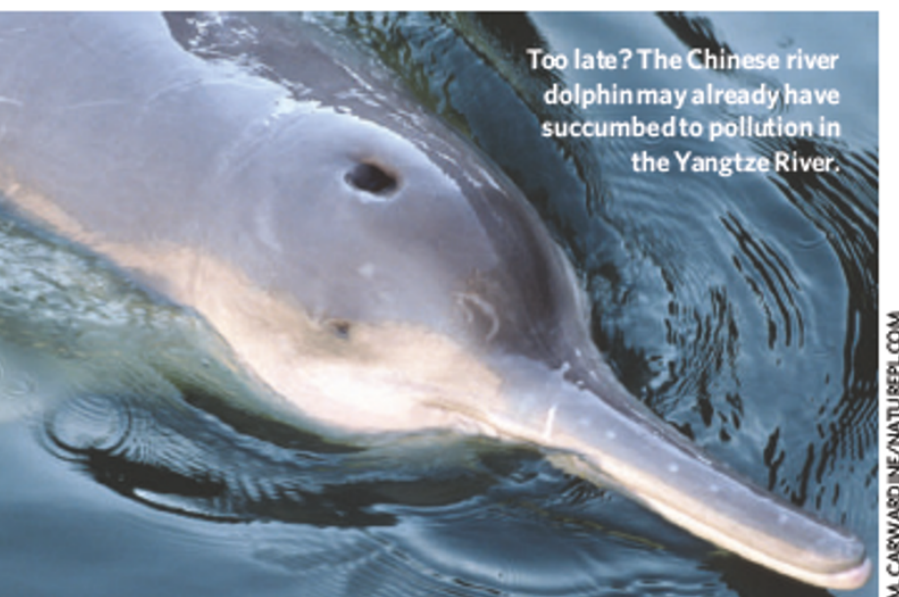

Too late? The Chinese river dolphin may already have succumbed to pollution in the Yangtze River.

\section{The world's most critically} endangered cetacean, the Chinese 'baiji' river dolphin, may finally have a chance of being saved from extinction. But itcould be too late; researchers whocarried outa nineday pilotsearch for the dolphins last month didn't find a single one.

The freshwater baiji (Lipotes vexillifer) once thrived in their only habitat, the Yangtze River, which runs though central China. But fewer than 100 dolphins are

\author{
thought to be left in the river, which \\ has become a busy, polluted \\ highway. "If the giant panda is \\ China's symbol of the destruction of \\ forests, the baiji stands for polluted \\ waters," says Wang Ding, from the \\ Wuhan Institute of Hydrobiology. \\ An international team of \\ scientists, led by Ding, is hoping \\ to catch the animals and release \\ them in a safer place, possibly \\ the Shishou reserve, which is a \\ 20-kilometre arm off the Yangtze.
}




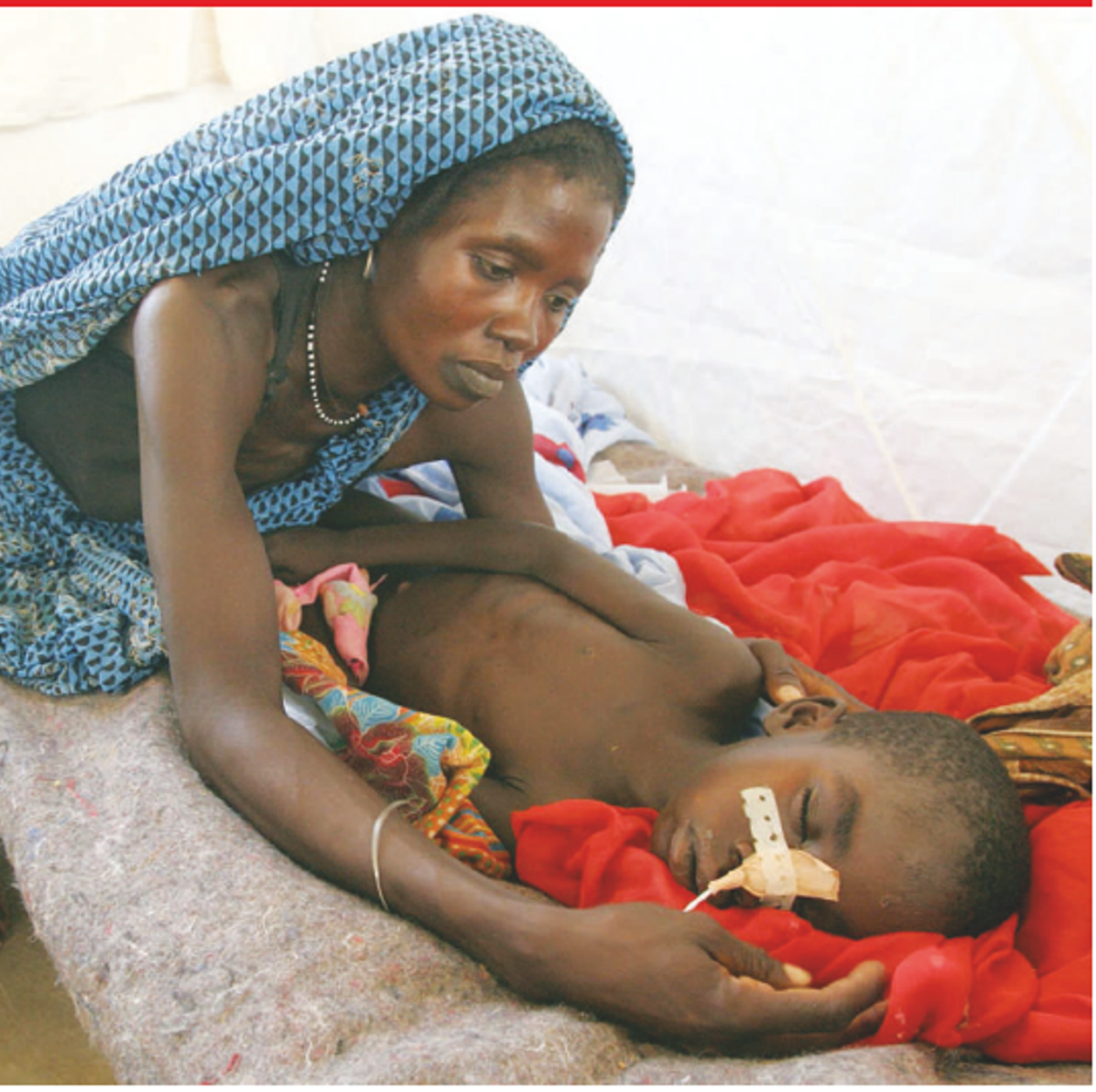

cheaper drug chloroquine. Resistance to chloroquine is rife among $P$. falciparum, but Attaran says that, in areas of India where both forms are prevalent, patients are treated with the drug anyway, with partial success.

Basu insists that this is in accordance with WHO recommendations. But Attaran and his co-authors retort that the bank should stop trying to lead global efforts against malaria and instead turn its funds over to dedicated health agencies such as the Global Fund to Fight AIDS, Tuberculosis and Malaria. "If you woke up with a fever, you wouldn't ring your bank for help, ${ }^{,}$Attaran says. ${ }^{\alpha}$ The World Bank is great at being a bank, but bad at being the world's doctor."

In 2004, Attaran criticized the US Agency for International Development over the handling of its $\$ 90$-million malaria budget (see Nature 435, 257; 2005), and he has argued angrily with World Bank officials in the past. A bank spokesman accuses Attaran of "waging war against the bank, The spokesman claims that Attaran refused a 2002 invitation to discuss the issue with bank officials.

Michael Hopkin
But first the researchers from China, the United States, Britain and Switzerland - need to find out exactly how many of the dolphins remain and where they are. They are preparing to conduct a search of 1,700 kilometres of the river in November, butcarried out a pilot survey in March to refine their techniques.

The baiji are so few and far between that the best way to spot them is with acoustic devices. But that's a challenge. "The river is so noisy you

\section{"If the giant panda is China's symbol of the destruction of forests, the baiji stands for polluted waters."}

can't use traditional acoustic equipment," explains Jay Barlow, a marine mammalogist from the US National Marine Fisheries Service in La Jolla, California, who was on last month's cruise. He and his colleagues are working on a method to clean up recordings from hydrophones, to isolate the baiji's distinctive whistles.

The researchers were disappointednot to see a single baijion their recent search, but their hopes are now focused on the full-scale survey in November. "If none are found then, the burden of proof will change," says Barlow. "The species will be considered extinct unless proven otherwise." Rex Dalton 